\title{
Aberrantly expressed transcription factors C/EBP and SOX4 have positive effects in the development of chronic myeloid leukemia
}

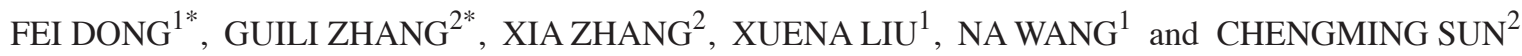 \\ ${ }^{1}$ School of Medicine, Qingdao University, Qingdao, Shandong 266000; ${ }^{2}$ Department of Laboratory Center, Yantai \\ Yuhuangding Hospital Affiliated to Qingdao University Medical College, Yantai, Shandong 264000, P.R. China
}

Received November 21, 2016; Accepted July 2, 2017

DOI: $10.3892 / \mathrm{mmr} .2017 .7486$

\begin{abstract}
The aim of the present study was to examine the expression and significance of CCAAT/enhancer binding protein $\alpha(\mathrm{C} / \mathrm{EBP} \alpha)$ and SRY-related high mobility group box containing transcription factor 4 (SOX4) in chronic myeloid leukemia (CML). Bone marrow samples were collected from patients with CML, and peripheral blood mononuclear cells were collected from healthy controls. Protein and mRNA were extracted from the collected samples, and analyzed using western blotting and reverse transcription-quantitative polymerase chain reaction analyses, respectively. Spearman's method was used to evaluate the correlation between the expression levels of these two genes, with $\mathrm{P}<0.05$ considered to indicate a statistically significant difference. A total of 79 patients, including 57 patients with newly diagnosed CML and 22 patients treated with imatinib therapy, and 30 controls were enrolled. The expression of SOX4 was upregulated in the patients with CML, whereas the expression of $\mathrm{C} / \mathrm{EBP} \alpha$ was downregulated $(\mathrm{P}<0.05)$. However, no differences were observed among the chronic, accelerated and blastic CML phases, respectively $(\mathrm{P}>0.05)$. In addition, no associations were found between the changes in expression and age, gender,
\end{abstract}

Correspondence to: Dr Chengming Sun, Department of Laboratory Center, Yantai Yuhuangding Hospital Affiliated to Qingdao University Medical College, 20 Yuhuangding Road, Zhifu, Yantai, Shandong 264000, P.R. China

E-mail: sunchengming516@hotmail.com

*Contributed equally

Abbreviations: $\mathrm{C} / \mathrm{EBP} \alpha, \mathrm{CCAAT} / \mathrm{enhancer}$ binding protein $\alpha$; CML, chronic myeloid leukemia; $\mathrm{CP}$, chronic phase; AP, accelerated phase; BP, blastic phase; ALL, acute lymphoblastic leukemia; SOX4, SRY-related high mobility group box containing transcription factor 4; CML-CP, chronic phase CML; CML-AP, accelerated phase CML; CML-BP, blastic phase CML; WBC, white blood cell; PB, peripheral blood; GAPDH, glyceraldehyde-3-phosphate dehydrogenase

Key words: chronic myeloid leukemia, SRY-related high mobility group box containing transcription factor 4, CCAAT/enhancer binding protein $\alpha$, target therapy white blood cells or the expression of breakpoint cluster region/abelson in patients $(\mathrm{P}>0.05)$. However, the expression of SOX4 was negatively correlated with the expression of $\mathrm{C} / \mathrm{EBP} \alpha(\mathrm{P}<0.01)$. Following imatinib treatment, the expression of SOX4 was downregulated in the progression-free patients, but upregulated in the blastic phase patients, whereas the expression of $\mathrm{C} / \mathrm{EBP} \alpha$ showed the opposite trend. Therefore, $\mathrm{C} / \mathrm{EBP} \alpha$ and SOX4 were important and negatively associated with the process of CML, and the $\mathrm{C} / \mathrm{EBP} \alpha-\mathrm{SOX} 4$ axis may be a novel potential therapeutic target for the treatment of CML.

\section{Introduction}

Chronic myeloid leukemia (CML) is a malignant myeloproliferative disorder characterized by reciprocal chromosomal translocation between chromosomes 9 and 22, which leads to the formation of the breakpoint cluster region-abelson (BCR/ABL) oncoprotein with constitutively active tyrosine kinase (1). According to its progression, CML can be divided into three phases: Chronic phase (CP), accelerated phase (AP) and blastic phase (BP), and the majority of cases are diagnosed in the CP (2). It has been demonstrated that, following allogeneic cell transplantation, the survival rate of patients with CML is significantly prolonged and may be cured; however, this treatment is only suitable for young patients with $\mathrm{CP}$ CML and fully matched human leukocyte antigen donors (3), whereas the mean age of diagnosis of CML is 64 years old (4). Due to the specific characteristic of CML, tyrosine kinase inhibitors targeting BCR/ABL have been developed, including imatinib. However, drug resistance has been found in patients with CML (5). To date, CML accounts for $15 \%$ of all cases of leukemia and affects $1 / 100,000$ individuals per year in Western countries (6). The prevalence of this disease is likely to increase in the future; therefore, it is essential to improve current understanding of the pathogenesis of CML.

Previous studies have demonstrated that the investigation of transcription factors is a useful and crucial method for understanding the mechanism of diseases. CCAAT/enhancer binding protein $\alpha(\mathrm{C} / \mathrm{EBP} \alpha)$ is a prototypical basic region-leucine zipper transcription factor, which acts as an oncogene in several types of cancer (7). C/EBP $\alpha$ has been reported to be involved in acute lymphoblastic leukemia (ALL) (8). Several studies have demonstrated that $\mathrm{C} / \mathrm{EBP} \alpha$ can regulate genes, which are key to cell differentiation in AML, and can inhibit cell cycle and 
apoptosis $(9,10)$. Zhang et al revealed that SRY-related high mobility group box containing transcription factor 4 (SOX4) is a direct downstream target and important mediator of $\mathrm{C} / \mathrm{EBP} \alpha$ in ALL (11), however, its mechanism in CML remains not to be elucidated. SOX4, which belongs to the SoxC class of transcription factors, primarily contributes to regulation of the proliferation and survival of mesenchymal and neural progenitors (9), B and T cell maturation (12), cardiac outflow formation and myeloid differentiation $(13,14)$. The aberrant expression of SOX4 in adult tissues has been linked to the occurrence and progression of cancer in humans and mice, and the overexpression of SOX4 is usually found in the majority of types of cancer, including bladder, hepatic, lung, gastric, prostate and hematopoietic cancer $(15,16)$. Ramezani-Rad et al demonstrated that SOX4 can act as a central mediator to enable oncogenic survival signals via phosphoinositide 3-kinase (PI3k)/AKT and mitogen-activated protein kinase (MAPK) signaling, which results in a poor clinical outcome in ALL (17).

In the present study, in order to investigate changes in SOX4 and $\mathrm{C} / \mathrm{EBP} \alpha$ in $\mathrm{CML}, 79$ patients with CML were enrolled. The expression of SOX4 and $\mathrm{C} / \mathrm{EBP} \alpha$ were compared between patients with CML and healthy controls, and the expression prior to and following imatinib treatment were compared in patients with CML. The aims of these investigations were to provide novel insight into CML targeted therapy.

\section{Materials and methods}

Patients and study design. Between January 2014 and October 2015, a total of 79 patients with CML, confirmed by morphology, immunology, cytogenetics and molecular biology (MICM) were enrolled at Yantai Yuhuangding Hospital Affiliated to Qingdao University Medical College (Yantai, China) for the present study. Among these, 57 patients had primary CML and had not received treatment. The male/female ratio of these patients was 31/26 and their median age was 56 years old. Based on the diagnostic results, the CML stages were confirmed as follows: 41 cases of newly diagnosed chronic phase CML (CML-CP), six cases of accelerated phase CML (CML-AP), 10 cases of blastic phase CML (CML-BP). Of the 79 patients, 22 patients were treated with imatinib, all of which had CML-CP. In addition, the white blood cell (WBC) levels and the expression levels of BCR/ABL in the patients with CML were determined. The peripheral blood (PB) mononuclear cells of 30 healthy individuals were also collected and used as controls. The Ethics Committee of Qingdao University Medical College authorized the present study and all patients provided signed informed consent.

Inclusion and exclusion criteria. Patients were enrolled if they met the following criteria: i) confirmation by MICM; ii) no other types of cancer or severe functional disease present; ii) no other blood disease present; iv) newly diagnosed and untreated, with the exception of those treated with imatinib; v) voluntarily participation and ability to complete treatment. Patients were excluded if they were $<18$ years of age or if their clinical information was incomplete.

Imatinib treatment. To receive imatinib therapy, patients were required to meet the following terms: i) Philadelphia chromosome-positive on bone marrow chromosome cultivation; ii) BCR/ABL mutant positive; iii) T315I mutant negative. The specification of imatinib in this study was $100 \mathrm{mg}$ per tablet. CML-CP and CML-AP patients orally received 4 tablets of imatinib once a day (400 mg/day), and CML-BP patients orally received 6 tablets of imatinib once a day (600 mg/day). During treatment, all patients were required to follow the advice of their doctor and underwent hematological examination every week, with genetic diagnosis and molecular diagnosis every 3 months. The observation period was adjusted until significant blood, genetic or molecular activity was present, and the drug was present from the initiation of treatment. Bone marrow samples were collected from the patients at initial diagnosis and 3 months following imatinib treatment.

Reverse transcription-quantitative polymerase chain reaction (RT-qPCR) analysis. To determine the mRNA levels of $\mathrm{C} / \mathrm{EBP} \alpha$ and SOX4, lymphocyte separation medium (Tianjin Hao Yang Biological Manufacture Co., Ltd., Tianjin, China) was used to separate mononuclear cells from the bone marrow and PB samples. TRIzol (Invitrogen; Thermo Fisher Scientific, Inc., Waltham, MA, USA) was used to extract RNA from the separated mononuclear cells and an Easy Taq ${ }^{\circledR}$ PCR kit (Beijing Transgen Biotech Co., Ltd., Beijing, China) was used for cDNA production. Primers of SOX4, glyceraldehyde-3-phosphate dehydrogenase (GAPDH), $\mathrm{C} / \mathrm{EBP} \alpha$ and $\beta$-actin were synthesized by Invitrogen; Thermo Fisher Scientific, Inc. (Table I), and the RT-PCR kit was purchased from Applied Biosystems; Thermo Fisher Scientific, Inc. The reactive sample for SOX4 was as follows: $10 \mu \mathrm{l} 2 \mathrm{X} \mathrm{Mix}, 0.5 \mu \mathrm{l}$ each primer (10 $\mu \mathrm{mol} / \mathrm{l})$, $1.0 \mu \mathrm{l}$ cDNA, and double distilled water to $20 \mu \mathrm{l}$; and the reactive conditions were as follows: $95^{\circ} \mathrm{C}$ for $10 \mathrm{~min}$; 39 cycles of $95^{\circ} \mathrm{C}$ for $31 \mathrm{sec}, 60^{\circ} \mathrm{C}$ for $1 \mathrm{~min} ; 65^{\circ} \mathrm{C}$ for $31 \mathrm{sec}$; and $72^{\circ} \mathrm{C}$ for $10 \mathrm{~min}$. The reactive sample for $\mathrm{C} / \mathrm{EBP} \alpha$ was as follows: $10.5 \mu \mathrm{l} 2 \mathrm{X}$ Mix, $0.5 \mu \mathrm{l}$ each primer (10 $\mu \mathrm{mol} / \mathrm{l}), 1.0 \mu \mathrm{l} \mathrm{cDNA}$ and double distilled water to $25 \mu \mathrm{l}$; and the reactive conditions were as follows: $94^{\circ} \mathrm{C}$ for $5 \mathrm{~min} ; 35$ cycles of $94^{\circ} \mathrm{C}$ for $45 \mathrm{sec}$; $6^{\circ} \mathrm{C}$ for $45 \mathrm{sec} ; 72^{\circ} \mathrm{C}$ for $30 \mathrm{sec}$; and $72^{\circ} \mathrm{C}$ for $10 \mathrm{~min}$. The reactive systems of GAPDH and $\beta$-actin were as follows: $10 \mu 12 \mathrm{X}$ Mix, $0.5 \mu \mathrm{l}$ each primer (10 $\mu \mathrm{mol} / \mathrm{l}), 1.0 \mu \mathrm{l} \mathrm{cDNA}$ and double distilled water to $20 \mu \mathrm{l}$; and the reactive conditions were as follows: $94^{\circ} \mathrm{C}$ for $5 \mathrm{~min} ; 35$ cycles of $94^{\circ} \mathrm{C}, 30 \mathrm{sec} ; 55^{\circ} \mathrm{C}$ for $30 \mathrm{sec} ; 72^{\circ} \mathrm{C}$ for $1 \mathrm{~min}$; and $72^{\circ} \mathrm{C}$ for $10 \mathrm{~min}$. Amplification was performed on a ABI 7500 PCR equipment (Applied Biosystems, USA), and the recorded data were subjected to statistical analysis to analyze the relative expression levels of the genes using $2^{-\Delta \Delta \mathrm{Cq}}$ method (18). GAPDH was used as the internal reference for SOX 4 and $\beta$-actin was used as the internal reference for $\mathrm{C} / \mathrm{EBP} \alpha$.

Western blot analysis. In order to investigate the protein levels of $\mathrm{C} / \mathrm{EBP} \alpha$ and $\mathrm{SOX} 4$, the separated mononuclear cells were dissociated in protein lysis buffer to extract proteins, and the protein concentrations were measured using the bicinchoninic acid method (Thermo Fisher Scientific, Inc.). The electrophoresis of proteins (20 ng) was performed on a 10\% SDS-PAGE gel and then transferred onto a nitrocellulose membrane. Following blocking with 5\% skim milk for $2 \mathrm{~h}$, the nitrocellulose membrane was incubated with rabbit anti-human SOX4 (cat. no. ab85204; 1:500; Abcam, Cambridge, MA, 
Table I. Primers and forecasted product sizes of genes detected using reverse transcription-quantitative polymerase chain reaction analysis.

\begin{tabular}{llc}
\hline Gene & \multicolumn{1}{c}{ Primer } & Product size (bp) \\
\hline SOX4 (NM_003107.2) & F: 5'-TTCAGCAACCAGCATTC-3' & 104 \\
GAPDH (NM_001289746.1) & R: 5'-TCCCTCTCTCTCGCTCTCTC-3' & 115 \\
$\beta$-actin (NM_001101.3) & F: 5'-CCCACTCCTCCACCTTTGAC-3' & \\
& R: 5'-ATGAGGTCCACCACCCTGTT-3' & 182 \\
C/EBP $\alpha$ (NM_004364.4) & F: 5'-GATCTGGCACCACACCTTCTAC-3' & \\
& R: 5'-AGGCATACAGGGACAGCACA-3' & 372 \\
& F: 5'-CACCGCTCCAATGCCTAC-3' & \\
\hline
\end{tabular}

SOX4, SRY-related high mobility group box containing transcription factor 4; GAPDH, glyceraldehyde-3-phosphate dehydrogenase; C/EBP $\alpha$, CCAAT/enhancer binding protein $\alpha ; F$, forward; $\mathrm{R}$, reverse.

USA) or rabbit anti-human GAPDH (cat. no. ab9485; 1:1,000; Abcam) at $4^{\circ} \mathrm{C}$ overnight and then washed three times with phosphate-buffered saline with Tween-20 (PBST). The nitrocellulose membrane was then incubated with goat anti-rabbit IgG (H+L)-HRP (cat. no. ab6721; 1:5,000; Abcam) at room temperature for $1 \mathrm{~h}$ and washed with PBST three times. Finally, an electro-chemiluminescence method was used to reveal the protein bands and Quantity One software (version 4.6.3; Bio-Rad Laboratories, Inc., Hercules, CA, USA) was utilized to analyze the gray values of protein bands.

Statistical analysis. Statistical analysis was performed using SPSS software (version 19.0; IBM SPSS, Armonk, NY, USA). Comparison of measurement data was performed using Student's t-test and the results are expressed as the mean \pm standard deviation. The comparison of enumeration data was performed using a $\chi^{2}$ test, and the correlation between two samples in patients with primary CML was determined using Spearman's method. $\mathrm{P}<0.05$ was considered to indicate a statistically significant difference.

\section{Results}

$C / E B P \alpha$ in patients with primary $C M L$. Based on the results of the RT-qPCR, the relative mRNA level of $\mathrm{C} / \mathrm{EBP} \alpha$ was significantly lower in the patients with primary CML, compared with that in the control group $(0.253 \pm 0.034$, vs. $0.811 \pm 0.0563$; $\mathrm{P}<0.01$; Fig. 1).

Associations between the expression of $C / E B P \alpha$ and gender, age, WBC and BCR/ABL in primary $C M L$. To further elucidate the associations between the expression of $\mathrm{C} / \mathrm{EBP} \alpha$ and known factors, including gender, age, WBC levels and expression levels of BCR/ABL, the patients with primary CML were divided into two groups according to $\mathrm{C} / \mathrm{EBP} \alpha / \beta$-actin $<0.5$, which was shown in all patients in the control group, and Pearson's $\chi^{2}$ test was performed. The results showed no significant association between the expression of $\mathrm{C} / \mathrm{EBP} \alpha$ and gender $(\mathrm{P}>0.05)$. In addition, no significant association was found between the expression of $\mathrm{C} / \mathrm{EBP} \alpha$ and age when the patients were separated into two groups by their median age

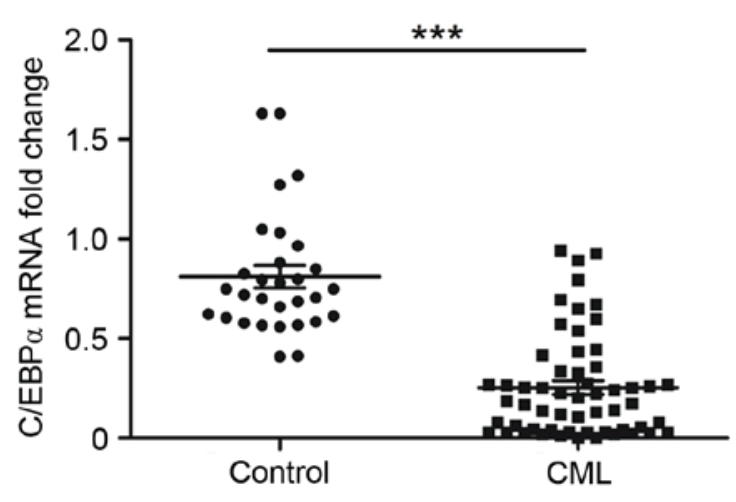

Figure 1. mRNA expression of $\mathrm{C} / \mathrm{EBP} \alpha$ detected using reverse transcription-quantitative polymerase chain reaction analysis. The mRNA expression of $\mathrm{C} / \mathrm{EBP} \alpha$ was significantly lower in patients with $\mathrm{CMR}$, compared with that in healthy controls. ${ }^{* * *} \mathrm{P}<0.001$ compared with the control group. $\mathrm{CML}$, chronic myeloid leukemia; $\mathrm{C} / \mathrm{EBP} \alpha, \mathrm{CCAAT} / \mathrm{enhancer}$ binding protein $\alpha$.

of 51.5 years $(\mathrm{P}>0.05)$. No significant association was identified between the expression of $\mathrm{C} / \mathrm{EBP} \alpha$ and $\mathrm{WBC}$ levels when the patients were divided into two groups by $\mathrm{WBC}>1 \times 10^{10}$ $(\mathrm{P}>0.05)$. In addition, no significant association was found between the expression of $\mathrm{C} / \mathrm{EBP} \alpha$ and BCR/ABL when the patients were divided into two groups according to the expression of $\mathrm{BCR} / \mathrm{ABL}(\mathrm{P}>0.05)$. The above results indicated that there were no significant associations between the expression of $\mathrm{C} / \mathrm{EBP} \alpha$ and gender, age, WBC levels or the expression of $\mathrm{BCR} / \mathrm{ABL}$ in primary CML (Table II).

Changes in the expression of $C / E B P \alpha$ in primary $C M L$ following imatinib treatment. Among the enrolled patients, a total of 22 CML patients accepted imatinib treatment. Following treatment, no improvements in condition were observed in 13 patients with CML, however, the expression of $\mathrm{C} / \mathrm{EBP} \alpha$ was significantly increased, compared with that prior to treatment $(0.314 \pm 0.0565$, vs. $0.111 \pm 0.0242 ; \mathrm{P}<0.01$; Fig. 2A). However, following treatment with imatinib, the expression of $\mathrm{C} / \mathrm{EBP} \alpha$ remained lower than that in the control group $(\mathrm{P}<0.05)$. In addition, nine cases of $\mathrm{CML}$ transformed into $\mathrm{BP} C \mathrm{CL}$ and the expression of $\mathrm{C} / \mathrm{EBP} \alpha$ was significantly 
Table II. Correlations between the expression of $\mathrm{C} / \mathrm{EBP} \alpha$ and gender, age, WBCs and BCR/ABL.

\begin{tabular}{lcccr}
\hline Index & Group & $\mathrm{C} / \mathrm{EBP} \alpha / \beta$-actin $<0.5$ & $\mathrm{C} / \mathrm{EBP} \alpha / \beta$-actin $\geq 0.05$ & $\chi^{2}$ \\
\hline Gender & Male & 27 & 6 & 0.063 \\
& Female & 19 & 5 & 0.802 \\
Age (years) & $\leq 51.5$ & 22 & 7 & 0.183 \\
& $>51.5$ & 25 & 3 & 2.900 \\
WBCs (n) & $\leq 1 \times 10^{10}$ & 11 & 0 & 0.089 \\
BCR/ABL $(\%)$ & $>1 \times 10^{10}$ & 36 & 10 & 0.574 \\
& $\leq 100$ & 25 & 4 & 6.449
\end{tabular}

$\mathrm{C} / \mathrm{EBP} \alpha, \mathrm{CCAAT} /$ enhancer binding protein $\alpha$; WBCs, white blood cells; BCR/ABL, breakpoint cluster region-abelson.

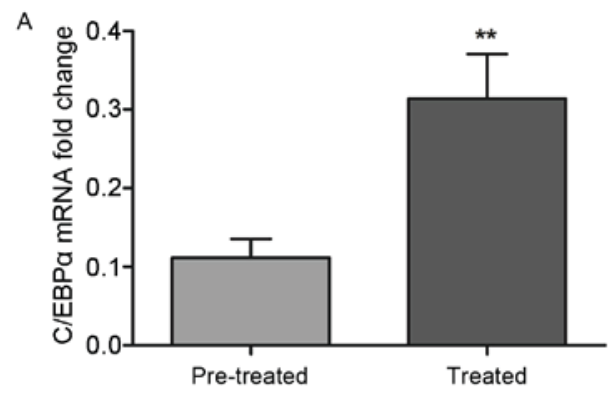

B

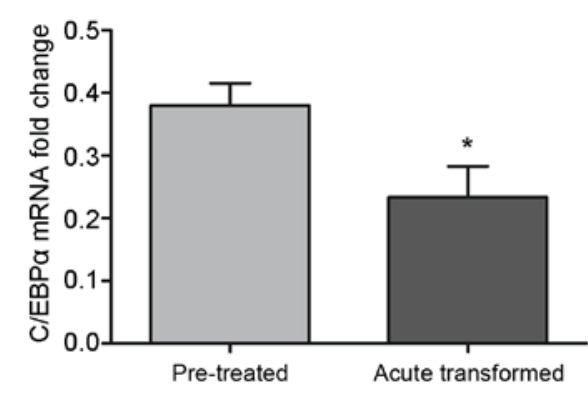

Figure 2. mRNA expression levels of C/EBP $\alpha$ prior to and following imatinib treatment. Following treatment with imatinib, the mRNA expression of $\mathrm{C} / \mathrm{EBP} \alpha$ was (A) significantly increased in $13 / 22$ patients with progression-free CML and (B) decreased in 9/22 patients with CML transformed into the blastic phase. ${ }^{*} \mathrm{P}<0.05$ and ${ }^{* *} \mathrm{P}<0.01$ compared with the pre-treated group. CML, chronic myeloid leukemia; $\mathrm{C} / \mathrm{EBP} \alpha, \mathrm{CCAAT} / \mathrm{enhancer}$ binding protein $\alpha$.

decreased following treatment, compared with the control (0.234 \pm 0.0493 , vs. $0.3798 \pm 0.0356 ; \mathrm{P}<0.05$; Fig. 2B).

SOX4 in patients with primary CML. According to the results of the RT-qPCR analysis, the mRNA level of SOX4 in the patients with primary CML was significantly higher, compared with that in the control group $(6.546 \pm 1.495$, vs. $0.0596 \pm 0.0187$; $\mathrm{P}<0.01$; Fig. 3A). Further subgroup investigation found no significant differences in the mRNA levels of SOX among the CML-CP, CML-AP and CML-BP patient groups ( $\mathrm{P}>0.05$; Fig. 3B). The protein level of SOX4 was also determined using western blot analysis. Similar to the mRNA levels, the protein expression of SOX4 in the primary CML group was significantly higher, compared with that in the control group $(\mathrm{P}<0.05$; Fig. $3 \mathrm{C}$ and $\mathrm{D})$.
Associations between the expression of SOX4 and gender, age, $W B C$ and $B C R / A B L$ in primary $C M L$. To investigate the associations between the expression of SOX4 and known factors, including gender, age, WBC levels and expression levels of $\mathrm{BCR} / \mathrm{ABL}$, the patients with primary $\mathrm{CML}$ were divided into two groups according to SOX4/GAPDH $<1$, which was shown in all patients in the control group. Pearson's $\chi^{2}$ test was performed, and the results revealed there was no significant association between the expression of SOX4 and gender ( $\mathrm{P}>0.05)$. In addition, no significant association was found between the expression of SOX4 and age when the patients were separated into two groups by the median age of 51.5 years $(\mathrm{P}>0.05)$. In addition, no significant association was observed between expression of SOX4 and WBC levels when the patients were divided into two groups by $\mathrm{WBC}>1 \times 10^{10}(\mathrm{P}>0.05)$. There was also no significant association between the expression of SOX4 and $\mathrm{BCR} / \mathrm{ABL}$ when the patients were divided into two groups according to the expression of BCR/ABL $(\mathrm{P}>0.05)$. The above data suggested that there were no significant associations between the expression of SOX4 and gender, age, WBC levels or the expression levels of BCLR/ABL in primary CML (Table III).

Changes in the expression of SOX4 in primary CML following imatinib treatment. As with $\mathrm{C} / \mathrm{EBP} \alpha$, the expression of SOX4 was also detected following imatinib treatment. The expression of SOX4 was significantly decreased following treatment, compared with expression prior to treatment, in the 13 patients with CML who were treated with imatinib $(0.601 \pm 0.315$, vs. 2.669 $\pm 0.758 ; \mathrm{P}<0.05$; Fig. 4A). However, following treatment with imatinib, the expression of SOX4 was higher, compared with that in the control group $(\mathrm{P}<0.05)$. The remaining nine patients with CML developed BP CML following treatment, and the expression of SOX4 was significantly increased compared with the expression prior to treatment $(0.648 \pm 0.157$, vs. $0.128 \pm 0.0338$; $\mathrm{P}<0.01$; Fig. 4B).

Correlation between the expression of SOX4 and C/EBP $\alpha$. To further determine the relevance of the expression of SOX4 and $\mathrm{C} / \mathrm{EBP} \alpha$, Spearman's correlation analysis was performed in the 57 cases of primary CML. The analytical outcome revealed that the expression of SOX4 was significantly negatively 
Table III. Correlations between the expression of SOX4 and gender, age, WBCs and BCR/ABL.

\begin{tabular}{|c|c|c|c|c|c|}
\hline Index & Group & SOX/GAPDH $<1$ & $\mathrm{SOX} / \mathrm{GAPDH} \geq 1$ & $\chi^{2}$ & P-value \\
\hline \multirow[t]{2}{*}{ Gender } & Male & 15 & 16 & 0.211 & 0.646 \\
\hline & Female & 11 & 15 & & \\
\hline \multirow[t]{2}{*}{ Age (years) } & $\leq 51.5$ & 15 & 14 & 0.888 & 0.346 \\
\hline & $>51.5$ & 11 & 17 & & \\
\hline \multirow[t]{2}{*}{ WBCs (n) } & $\leq 1 \times 10^{10}$ & 3 & 9 & 2.604 & 0.107 \\
\hline & $>1 \times 10^{10}$ & 23 & 22 & & \\
\hline \multirow[t]{2}{*}{ BCR/ABL (\%) } & $\leq 100$ & 12 & 18 & 0.805 & 0.370 \\
\hline & $>100$ & 14 & 13 & & \\
\hline
\end{tabular}

SOX4, SRY-related high mobility group box containing transcription factor 4; WBCs, white blood cells; BCR/ABL, breakpoint cluster region-abelson.

A

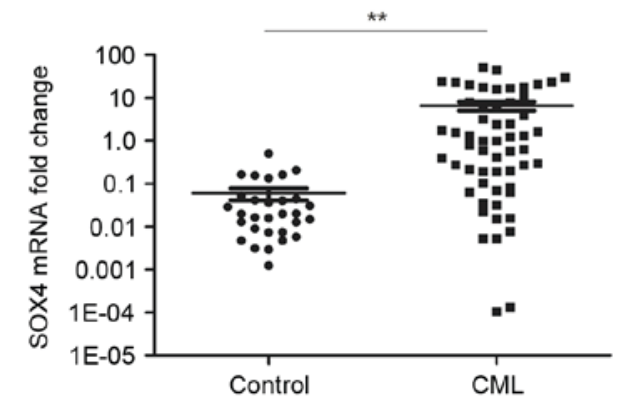

C

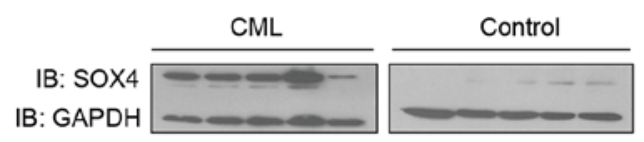

B

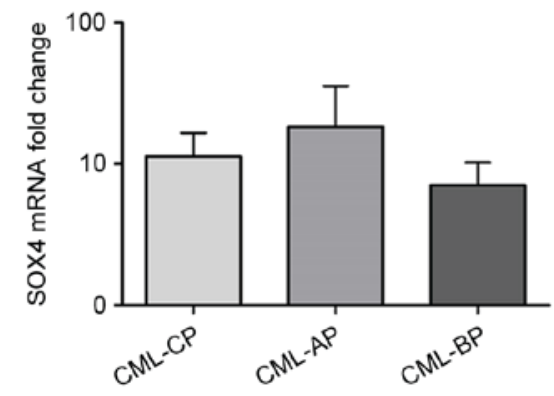

D

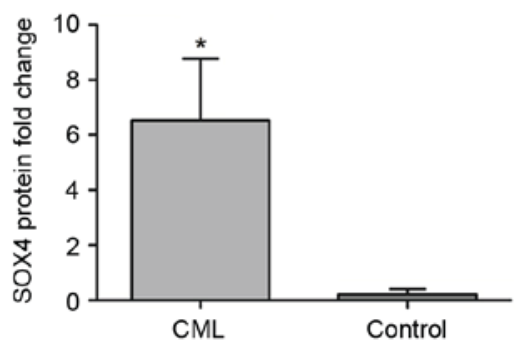

Figure 3. Expression of SOX4 in healthy controls and patients with CML. The results of the reverse transcription-quantitative polymerase chain reaction analysis showed that (A) the mRNA expression of SOX4 was higher in patients with CML, compared with that in healthy controls. (B) No significant difference in SOX4 was observed among patients with CML-CP, CML-AP and CML-BP. (C) Protein expression of SOX4 was increased in patients with CML, compared with that in healthy controls. (D) Quantification of protein expression revealed a significant difference. ${ }^{*} \mathrm{P}<0.05$ and ${ }^{* *} \mathrm{P}<0.01$ compared with the control group. CML, chronic myeloid leukemia; CP, chronic phase; AP, accelerated phase; BP, blastic phase; SOX4, SRY-related high mobility group box containing transcription factor 4; GAPDH, glyceraldehyde-3-phosphate dehydrogenase.

correlated with the expression of $\mathrm{C} / \mathrm{EBP} \alpha$ in patients with CML (Fig. 5).

\section{Discussion}

CML is a myeloproliferative disorder originating from hematopoietic stem cells with constitutive expression of the BCR/ABL oncoprotein (19). Imatinib was the first target drug approved by the US Food and Drug administration for the treatment of CML, and remains a commonly used drug in clinical therapy (20). In the present study, $\mathrm{C} / \mathrm{EBP} \alpha$ was found to be markedly downregulated in patients with $\mathrm{CML}$, compared with healthy controls, whereas the opposite was found for SOX4. The changes in the expression of $\mathrm{C} / \mathrm{EBP} \alpha$ and SOX4 were not associated with the age, gender, WBC level or the expression of BCR/ABL. Following treatment with imatinib, the expression of $\mathrm{C} / \mathrm{EBP} \alpha$ was increased and the expression of SOX4 was decreased in 13/22 patients with CML, which were progression-free. The opposite was observed in the expression levels of $\mathrm{C} / \mathrm{EBP} \alpha$ and SOX4 in the remaining nine patients with CML, which developed into CML-BP. In addition, the relative expression analysis showed that the expression of $\mathrm{C} / \mathrm{EBP} \alpha$ was negatively correlated with that of SOX4 in CML.

Myelopoiesis is the process by which myeloid progenitor cells differentiate into myeloid cells, including eosinophils, monocytes and granulocytes. $\mathrm{C} / \mathrm{EBP} \alpha$ is crucial in addition to other myeloid transcription factors in this process (21). A previous study reported that mutation of the $\mathrm{C} / \mathrm{EBP} \alpha$ gene was present in 


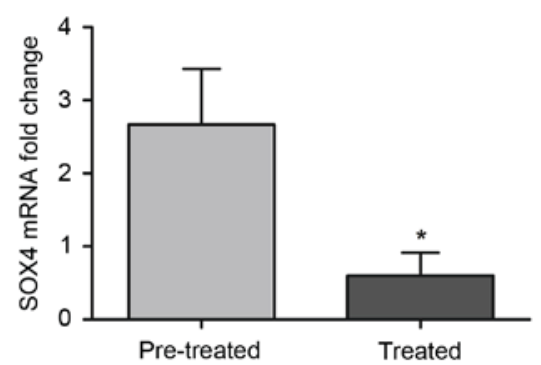

B

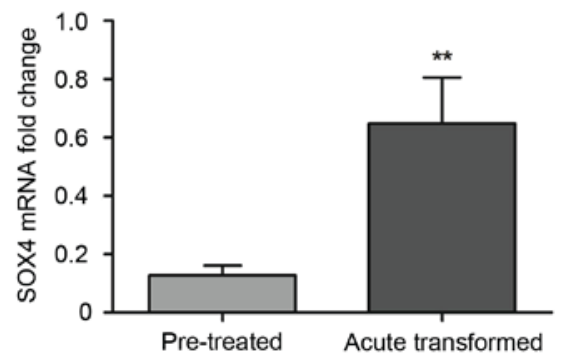

Figure 4. mRNA expression levels of SOX4 prior to and following imatinib treatment. Following treatment with imatinib, the mRNA expression of SOX4 was (A) significantly decreased in $13 / 22$ patients with progression-free CML and (B) significantly increased in $9 / 22$ of patients with CML transformed into the blastic phase. ${ }^{*} \mathrm{P}<0.05$ and $^{* *} \mathrm{P}<0.01$ compared with the pre-treated group. CML, chronic myeloid leukemia; SOX4, SRY-related high mobility group box containing transcription factor.

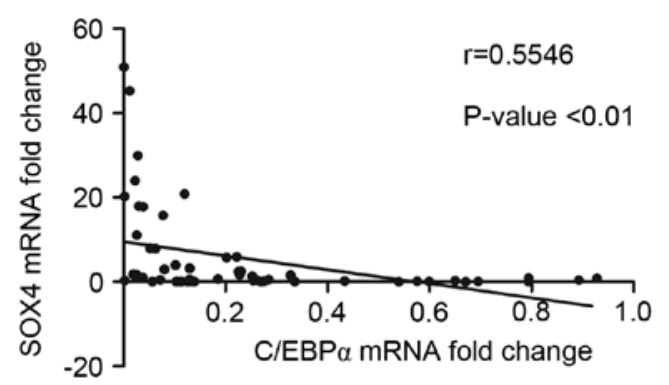

Figure 5. Correlation in the expression of C/EBP $\alpha$ and SOX4 in CML. Based on Spearman's correlation, a significant negative correlation was identified between the expression of C/EBP $\alpha$ and the expression of SOX4 in patients with CML. CML, chronic myeloid leukemia; $\mathrm{C} / \mathrm{EBP} \alpha, \mathrm{CCAAT} / \mathrm{enhancer}^{-}$ binding protein $\alpha$; SOX4, SRY-related high mobility group box containing transcription factor 4.

$\sim 5-14 \%$ of patients with AML (10). The mutation or deletion of $\mathrm{C} / \mathrm{EBP} \alpha$ may result in arrest of the transit of common myeloid progenitors into granulocyte-monocyte progenitors, and lead to a reduction in granulocytes and monocytes (22). In addition, deficiency of C/EBP $\alpha$ in mice may induce disorder in myeloproliferation (19). In the present study, significantly lower expression of $\mathrm{C} / \mathrm{EBP} \alpha$ was detected in patients with CML, compared with that in normal controls. Epigenic modification is recognized as an important mechanism in regulating the expression of specific genes, which are associated with leukemogenesis (23), and Chim et al (24) reported that $\mathrm{C} / \mathrm{EBP} \alpha$ was hypermethylated in its promoter in patients with AML. Therefore, methylation may cause the downregulation of C/EBP $\alpha$. This was confirmed by Annamaneni et al (25), who reported that the aberrant methylation of the $\mathrm{C} / \mathrm{EBP} \alpha$ promoter is a common event in CML.
Theil et al (26) demonstrated that EZH2 acts as an oncogene to improve the methylation of $\mathrm{C} / \mathrm{EBP} \alpha$, and thus inhibit myeloid differentiation. Ubiquitination is another essential mechanism for the downregulation of C/EBP $\alpha$. Tribl and 2 are two identified Tribbles family members, which can act as adapters to recruit $\mathrm{E} 3$ ligases to mediate ubiquitin degradation and inactivation (27). Therefore, the downregulation of $\mathrm{C} / \mathrm{EBP} \alpha$ may be a result of methylation and ubiquination, and this change may be crucial during the process of CML.

SOX 4 has been reported to be directly regulated by $\mathrm{C} / \mathrm{EBP} \alpha$, and to be important in the normal differentiation of myeloid and lymphoid lineages (14). It has been shown that $\mathrm{C} / \mathrm{EBP} \alpha$ can suppress the expression of SOX4 via directly binding to its promoter, and the transition of leukemia caused by C/EBPa mutation can be partially reversed by downregulating SOX4 $(11,28)$. The present study also revealed significantly upregulated mRNA and protein expression levels of SOX in patients with CML, compared with levels in normal controls, and SOX4 was negatively correlated with $\mathrm{C} / \mathrm{EBP} \alpha$. This suggested that the upregulated mRNA and protein levels of SOX4 may have been caused by the downregulation of C/EBP $\alpha$. Aue et al (29) demonstrated that the overexpression of SOX4 induces myeloid leukemia via cooperating with the haplo-insufficiency of PU.1, which is an important regulator of the proliferation and differentiation of hematopoietic stem cells. The overexpression of SOX4 can inhibit the differentiation of myeloid progenitor cells (30). Ramezani-Rad et al (17) revealed that SOX4 activates the PI3K/AKT and MAPK signaling pathways to enhance survival signaling, and these signaling pathways are required for the survival, progression and proliferation of pre-B ALL. However, whether this signaling pathway is associated with CML remains to be elucidated and further investigations are required. Taken together, these results indicate that aberrant hypermethylation of the $\mathrm{C} / \mathrm{EBP} \alpha$ promoter may lead to the downregulation of $\mathrm{C} / \mathrm{EBP} \alpha$, and this downregulation may have a positive effect on the expression of SOX4. The resulting excessive expression of SOX4 may lead to the dys-proliferation of myeloid and lymphoid lineages, and result in the occurrence and development of CML. In the present study, this molecular pathway was referred to as the $\mathrm{C} / \mathrm{EBP} \alpha-\mathrm{SOX} 4$ axis.

To further elucidate the correlation between the $\mathrm{C} / \mathrm{EBP} \alpha-\mathrm{SOX} 4$ axis and BCR/ABL, comparisons were made in 22 CML patients who received imatinib treatment. The results showed that the expression of SOX4 was decreased in the progression-free patients, but increased in the acute transformed patients. By contrast, the expression of C/EBP $\alpha$ was increased in the progression-free patients, but decreased in the acute transformed patients following treatment. Although the expression levels of $\mathrm{C} / \mathrm{EBP} \alpha$ and SOX4 in 13 cases of CML improved, the stages of the patients remained unchanged or worsened. It is known that imatinib is a BCR/ABL-targeting drug, and the conditions of patients with CML can be improved following therapy (31). However, the diagnostic results were not in accordance with this. This indicates that the signaling pathway of the $\mathrm{C} / \mathrm{EBP} \alpha-\mathrm{SOX} 4$ axis involved in CML was not in accordance with the signaling pathway of BCR/ABL. In addition, the analyses of individual factors demonstrated that the expression levels of $\mathrm{C} / \mathrm{EBP} \alpha$ and SOX4 were not correlated with the expression of $\mathrm{BCR} / \mathrm{ABR}$. Therefore, the C/EBP $\alpha-\mathrm{SOX} 4$ axis may be a novel therapeutic target in CML, differing from the BCR/ABL target. 
Another change in gene expression following imatinib treatment requires mention. Following treatment for 3 months, the expression of $\mathrm{C} / \mathrm{EBP} \alpha$ was significantly increased, compared with the expression prior to treatment. However, the mean level remained lower than that in the healthy controls. Although the expression of SOX4 was decreased, the mean level remained higher than that in the healthy controls. These results may indicate that $\mathrm{SOX} 4$ and $\mathrm{C} / \mathrm{EBP} \alpha$ served critical roles in the treatment of CML with imatinib. However, due to the short treatment duration, the overall condition of the patients remained below that in the healthy controls. Therefore, long-term evaluations of $\mathrm{C} / \mathrm{EBP} \alpha$ and $\mathrm{SOX} 4$ require consideration in subsequent investigations.

In conclusion, the $\mathrm{C} / \mathrm{EBP} \alpha-\mathrm{SOX} 4$ axis was found to be important in the process of CML. Due to methylation, the expression of $\mathrm{C} / \mathrm{EBP} \alpha$ was downregulated in $\mathrm{CML}$ and this downregulation induced an upregulation in the expression of SOX4. However, these changes were not correlated with the expression of $\mathrm{BCR} / \mathrm{ABL}$. Therefore, the $\mathrm{C} / \mathrm{EBP} \alpha-\mathrm{SOX} 4$ axis may be a novel therapeutic target for the treatment of CML.

\section{Acknowledgements}

The present study was supported by the Natural Science Foundation of Shandong Province (grant no. ZR2015HM073). The authors would like to thank the Biological Chip Laboratory of Yantai Yuhuangding Hospital.

\section{References}

1. Druker BJ, Talpaz M, Resta DJ, Peng B, Buchdunger E, Ford JM Lydon NB, Kantarjian H, Capdeville R, Ohno-Jones S and Sawyers CL: Efficacy and safety of a specific inhibitor of the BCR-ABL tyrosine kinase in chronic myeloid leukemia. N Engl J Med 344: 1031-1037, 2001.

2. Sawyers CL: Chronic myeloid leukemia. N Engl J Med 340: 1330-1340, 1999.

3. Pavlu J, Szydlo RM, Goldman JM and Apperley JF: Three decades of transplantation for chronic myeloid leukemia: What have we learned? Blood 117: 755-763, 2011.

4. Howlader N, Noone AM, Krapcho M, Newman N, Aminou R, Waldron W, Altekruse SF, Kosary CL, Ruhl J, Tatalovich Z, et al (eds): SEER Cancer Statistics Review, 1975-2009 (Vintage 2009 Populations). National Cancer Institute, Bethesda, MD. Based on November 2011 SEER data submission, posted to the SEER web site, April 2012. https://seer.cancer.gov/archive/ csr/1975_2009_pops09/

5. Parker WT, Ho M, Scott HS, Hughes TP and Branford S: Poor response to second-line kinase inhibitors in chronic myeloid leukemia patients with multiple low-level mutations, irrespective of their resistance profile. Blood 119: 2234-2238, 2012.

6. Apperley JF: Chronic myeloid leukaemia. Lancet 385: 1447-1459, 2015.

7. Friedman $\mathrm{AD}: \mathrm{C} / \mathrm{EBP} \alpha$ in normal and malignant myelopoiesis. Int J Hematol 101: 330-341, 2015.

8. Zeisig BB, Kulasekararaj AG, Mufti GJ and So CW: SnapShot: Acute myeloid leukemia. Cancer Cell 22: 698.e1, 2012.

9. Bhattaram P, Penzo-Méndez A, Sock E, Colmenares C, Kaneko KJ, Vassilev A, Depamphilis ML, Wegner M and Lefebvre V: Organogenesis relies on SoxC transcription factors for the survival of neural and mesenchymal progenitors. Nat Commun 1: 9, 2010

10. Song G, Wang L, Bi K and Jiang G: Regulation of the C/EBP $\alpha$ signaling pathway in acute myeloid leukemia (Review). Oncol Rep 33: 2099-2106, 2015.

11. Zhang H, Alberich-Jorda M, Amabile G, Yang H, Staber PB, Di Ruscio A, Welner RS, Ebralidze A, Zhang J, Levantini E, et al: Sox4 is a key oncogenic target in $\mathrm{C} / \mathrm{EBP} \alpha$ mutant acute myeloid leukemia. Cancer Cell 24: 575-588, 2013.
12. Kuwahara M, Yamashita M, Shinoda K, Tofukuji S, Onodera A, Shinnakasu R, Motohashi S, Hosokawa H, Tumes D, Iwamura C, et al: The transcription factor Sox 4 is a downstream target of signaling by the cytokine TGF- $\beta$ and suppresses TH2 differentiation. Nat Immunol 13: 778-786, 2012.

13. Aue G, Du Y, Cleveland SM, Smith SB, Davé UP, Liu D, Weniger MA, Metais JY, Jenkins NA, Copeland NG and Dunbar CE: Sox4 cooperates with PU.1 haploinsufficiency in murine myeloid leukemia. Blood 118: 4674-4681, 2011.

14. Sandoval S, Kraus C, Cho EC, Cho M, Bies J, Manara E, Accordi B, Landaw EM, Wolff L, Pigazzi M and Sakamoto KM: Sox4 cooperates with CREB in myeloid transformation. Blood 120: 155-165, 2012

15. Vervoort S, van Boxtel R and Coffer PJ: The role of SRY-related HMG box transcription factor 4 (SOX4) in tumorigenesis and metastasis: Friend or foe? Oncogene 32: 3397-3409, 2013.

16. Jafarnejad SM, Ardekani GS, Ghaffari M and Li G: Pleiotropic function of SRY-related HMG box transcription factor 4 in regulation of tumorigenesis. Cell Mol Life Sci 70: 2677-2696, 2013.

17. Ramezani-Rad P, Geng H, Hurtz C, Chan LN, Chen Z, Jumaa H, Melnick A, Paietta E, Carroll WL, Willman CL, et al: SOX4 enables oncogenic survival signals in acute lymphoblastic leukemia. Blood 121: 148-155, 2013.

18. Livak KJ and Schmittgen TD: Analysis of relative gene expression data using real-time quantitative PCR and the 2(-Delta Delta C(T)) method. Methods 25: 402-408, 2001.

19. Suknuntha K, Ishii Y, Tao L, Hu K, McIntosh BE, Yang D, Swanson S, Stewart R, Wang JY, Thomson J and Slukvin I: Discovery of survival factor for primitive chronic myeloid leukemia cells using induced pluripotent stem cells. Stem Cell Res 15: 678-693, 2015.

20. Bauer S, Buchanan S and Ryan I: Tyrosine kinase inhibitors for the treatment of chronic-phase chronic myeloid leukemia: Long-term patient care and management. J Adv Pract Oncol 7: 42-54, 2016.

21. Porse BT, Bryder D, Theilgaard-Mönch K, Hasemann MS, Anderson K, Damgaard I, Jacobsen SE and Nerlov C: Loss of $\mathrm{C} / \mathrm{EBP} \alpha$ cell cycle control increases myeloid progenitor proliferation and transforms the neutrophil granulocyte lineage. J Exp Med 202: 85-96, 2005.

22. Zhang P, Iwasaki-Arai J, Iwasaki H, Fenyus ML, Dayaram T, Owens BM, Shigematsu H, Levantini E, Huettner CS, Lekstrom-Himes JA, et al: Enhancement of hematopoietic stem cell repopulating capacity and self-renewal in the absence of the transcription factor C/EBP alpha. Immunity 21: 853-863, 2004.

23. Baer C, Claus R, Frenzel LP, Zucknick M, Park YJ, Gu L, Weichenhan D, Fischer M, Pallasch CP, Herpel E, et al: Extensive promoter DNA hypermethylation and hypomethylation is associated with aberrant microRNA expression in chronic lymphocytic leukemia. Cancer Res 72: 3775-3785, 2012.

24. Chim C, Wong AS and Kwong YL: Infrequent hypermethylation of CEBPA promotor in acute myeloid leukaemia. Br J Haematol 119: 988-990, 2002.

25. Annamaneni S, Kagita S, Gorre M, Digumarti RR, Satti V and Battini MR: Methylation status of CEBPA gene promoter in chronic myeloid leukemia. Hematology 19: 42-44, 2014.

26. Thiel AT, Feng Z, Pant DK, Chodosh LA and Hua X: The trithorax protein partner menin acts in tandem with EZH2 to suppress $\mathrm{C} / \mathrm{EBP} \alpha$ and differentiation in MLL-AF9 leukemia. Haematologica 98: 918-927, 2013.

27. Dedhia PH, Keeshan K, Uljon S, Xu L, Vega ME, Shestova O, Zaks-Zilberman M, Romany C, Blacklow SC and Pear WS: Differential ability of Tribbles family members to promote degradation of C/EBPalpha and induce acute myelogenous leukemia. Blood 116: 1321-1328, 2010.

28. Fung TK, Leung AY and So CW: Sox4you: A new player in C/EBPa leukemia. Cancer cell 24: 557-559, 2013.

29. Aue G, Du Y, Cleveland SM, Smith SB, Davé UP, Liu D, Weniger MA, Metais JY, Jenkins NA, Copeland NG and Dunbar CE: Sox4 cooperates with PU.1 haploinsufficiency in murine myeloid leukemia. Blood 118: 4674-4681, 2011.

30. Du Y, Spence SE, Jenkins NA and Copeland NG: Cooperating cancer-gene identification through oncogenic-retrovirus-induced insertional mutagenesis. Blood 106: 2498-2505, 2005.

31. Hanfstein B, Shlyaknto V, Lauseker M, Hehlmann R, Saussele S, Dietz C, Erben P, Fabarius A, Proetel U, Schnittger S, et al: Velocity of early BCR-ABL transcript elimination as an optimized predictor of outcome in chronic myeloid leukemia (CML) patients in chronic phase on treatment with imatinib. Leukemia 28: 1988-1992, 2014. 